\title{
Internet of Things (loT) realization in the context of industry 4.0 (i 4.0)
}

\begin{abstract}
At the dawn of the nineteenth century, the human civilization inaugurated a new era in production called as the Industrial Revolution. Following this line of thought, the first industrial revolution, located at the transition from the eighteenth to nineteenth centuries, was characterized by the introduction of water and steam-powered mechanical manufacturing facilities. The second industrial revolution, which happened at the transition from the nineteenth to twentieth century's, was based on the introduction of electrically powered mass production. Then followed the third industrial revolution, started from the 1960s until the 1990s, whose main driving force was the usage of electronics and information technologies (IT) to achieve further automation of manufacturing. These three successive revolutions can be coined as Industry 1.0, Industry 2.0, and Industry 3.0, respectively, see Figure 1. Currently, we are in the fourth industrial revolution (industry 4.0), whose main characteristic is the linkage of real objects and people (things) with information-processing/virtual objects via information networks utilizing technologies such as cyber-physical systems, Internet of things, 3D printing, artificial intelligence (AI), cloud computing, etc.. One Important component in this context is the advanced automation technology that will lead to the introduction of methods of self-organized systems (self-optimization, self-configuration, self-diagnosis, etc.) to get the suitable linkage between the real (machines, sensors, workers) and the virtual worlds. The term "industry 4.0" appeared for the first time in 2011 during the Hannover Fair, as a project in high-tech strategy of the German Industry, and in the following year was created the German Working Group on Industry4.0, which delivered its final report in April 2013. This report defined the Industry 4.0 environment, which includes the strong customization of products under the conditions of high flexibility of mass production. The term was definitively adopted at the 2015 World Economic Forum (WEF) annual meeting held in January 2015 in Davos, Switzerland.
\end{abstract}

Keywords: New era, Mechanical manufacturing, Steam powered, Industrial revolution
Volume 3 Issue 7 - 2017

Labib M Zawra
Benha University, Egypt

Correspondence: Labib M Zawra, Benha University, Egypt, Email lzawra@gmail.com

Received: November 24, 2017 | Published: December 22, 2017

\section{Integration between industry 4.0 and IoT}

Industry 4.0 will provide intelligence and communication for smart systems. Smart systems that includes; smart cities, smart factories, and smart grids have become the epitome of the modern technology. Smart systems, one of the facets of Industry 4.0, will revolutionize the sector tremendously. Recent reports indicate that the economic impact on the German industry will result in an added gross value of 267 billion euros by 2025 after introducing the industry 4. A comparison between Today's factory and future (Industry 4.0 based) factory is presented in Table 1 . However, there will be a need for seamless communication between these smart systems. Internet of Things (IoT) will provide the requisite communication infrastructure to facilitate communication between the increased number of sensors (things) and systems. IoT will utilize the internet protocol version 6 (IPv6). IPv6 is being preferred because it creates addressing capacity of $2^{\wedge 128}$ individual addresses. Therefore, each and every smart device will be assigned a unique IP-address. IPv6 will enable allowing the limitless addition of devices on the Internet, which is the idea behind Internet of Things concept. IPv6, which will improve the performance of cyber-physical systems, one of the facets of Industry 4.0. Applying the same idea on manufacturing environment will enable automation system builders to integrate huge number of sensors, controllers and products under one common platform. ${ }^{1-4}$
The successful implementation of Industry 4.0 depends on the type of Internet of Things technologies currently being implemented in the IT world. Presently, there are a number of technologies that have made it possible to convert physical objects into intelligent things. These technologies include Radio Frequency Identification (RFID), Internet Protocol (IP), Electronic Product Code (EPC), Barcode, Wireless Fidelity (Wi-Fi), Bluetooth, ZigBee, Near Field Communication (NFC), and actuators. For example automotive and aerospace companies are using RFID to improve the logistics of their supply chain. As IoT will help these companies receive detailed and up to date information about their logistics and supply chain. These technologies and others being developed will define how Industry 4.0 will be implemented. IoT technologies also will help developers to develop applications that will provide services that can be used to implement industrial automation systems. Some of the services include identity-related, information aggregation, collaborative aware and ubiquitous services. Identity-related services will enable the identification of an object through a special identifier such as an RFID tag. Information aggregation services will utilize IoT technology such as ZigBee that can collect data from sensors, process, and transmit it to a desired application. Collaborative aware services make decisions based on the collected aggregated data. Ubiquitous services will enable the deployment of IoT applications anywhere and offer a complete control. IoT technology will ensure systems established in Industry 
4.0 are of low cost and have lean operating system. IoT technology also will trigger unprecedented changes in Industry 4.0. Therefore, industry players must take prerequisite actions before Industry 4.0 goals are actualized. ${ }^{5-8}$

Table I A comparison between Today's factory and Industry 4.0 factory

\begin{tabular}{|c|c|c|c|c|c|}
\hline & \multirow[t]{2}{*}{$\begin{array}{l}\text { Data } \\
\text { Source }\end{array}$} & \multicolumn{2}{|l|}{ Today's factory } & \multicolumn{2}{|l|}{ Industry 4.0} \\
\hline & & Attributes & Technologies & Attributes & Technologies \\
\hline Component & sensor & Precision & $\begin{array}{l}\text { Smart sensors and facult } \\
\text { detection }\end{array}$ & $\begin{array}{l}\text { Self-aware } \\
\text { Self-predict }\end{array}$ & \\
\hline Machine & Controller & $\begin{array}{l}\text { Producibility \& } \\
\text { performance }\end{array}$ & $\begin{array}{l}\text { Condition-based } \\
\text { monitoring \& } \\
\text { diagnostics }\end{array}$ & $\begin{array}{l}\text { Self-aware } \\
\text { Self-predict } \\
\text { Self- } \\
\text { compare }\end{array}$ & $\begin{array}{l}\text { Degradation monitoring \&remaining useful life } \\
\text { prediction Up time with predictive health monitoring }\end{array}$ \\
\hline & & & & $\begin{array}{l}\text { Self- } \\
\text { configure }\end{array}$ & \\
\hline $\begin{array}{l}\text { Production } \\
\text { system }\end{array}$ & $\begin{array}{l}\text { Networked } \\
\text { system }\end{array}$ & $\begin{array}{l}\text { Productivity \& } \\
\text { OEE }\end{array}$ & $\begin{array}{l}\text { Lean operations work } \\
\text { and waste reduction }\end{array}$ & $\begin{array}{l}\text { Self- } \\
\text { maintain }\end{array}$ & Worry-free productivity \\
\hline & & & & $\begin{array}{l}\text { Self- } \\
\text { organize }\end{array}$ & \\
\hline
\end{tabular}

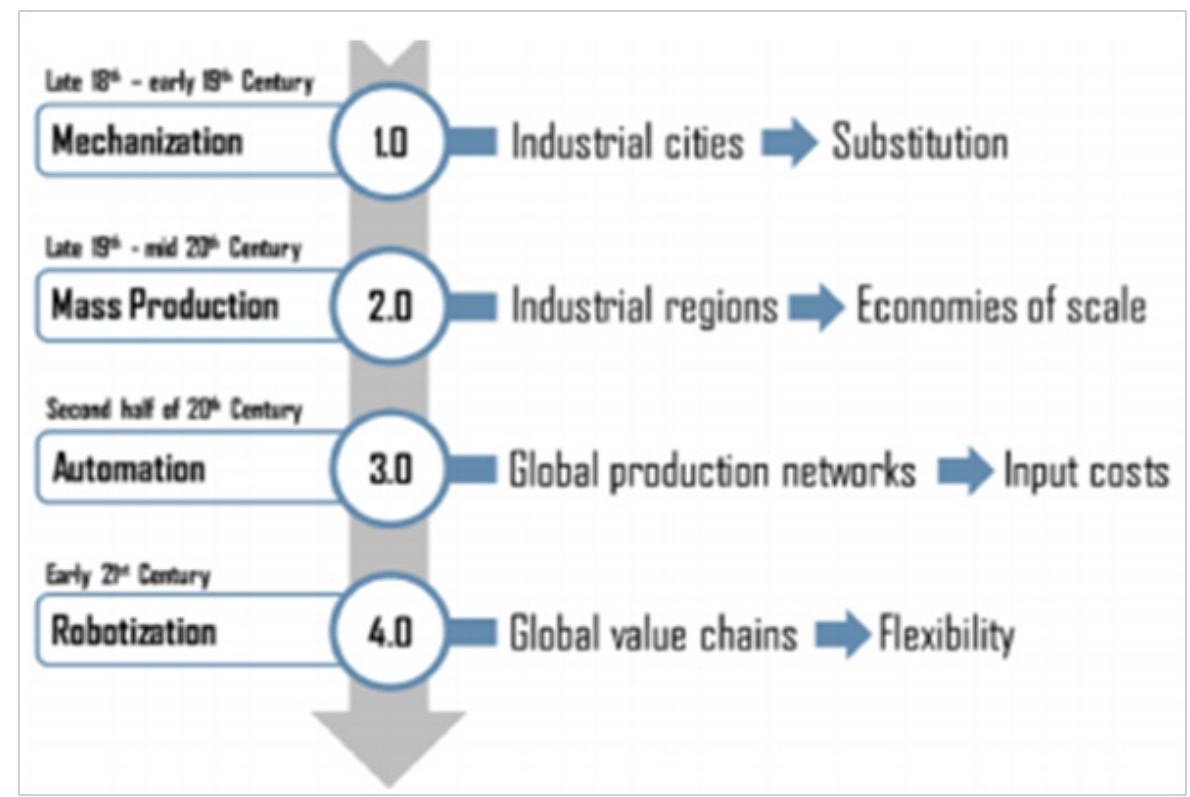

Figure I The four industrial revolutions.

\section{Acknowledgments}

No acknowledgement

\section{Conflicts of interest}

No conflict of interest.

\section{References}

1. Ing Reiner Anderl. Industrie 4.0-Advanced Engineering of Smart Products and Smart Production. Int Semin High Technol. 2014.

2. Devezas T, Leitao J, Sarygulov A. Industry 4.0: Entrepreneurship and Structural Change in the New Digital Landscape Studies on Entrepreneurship, Structural Change and Industrial Dynamics. Springer. 2017. p. $1-10$.
3. Roblek V, Meško M, Krapež A. A Complex View of Industry 4.0. SAGE Open. 2016;6(2):1-11.

4. Shemshadi A, Sheng QZ, Zhang WE, et al. Searching for the Internet of Things on the Web: Where It Is and What It Looks Like. 2016.

5. Gigli M. Internet of Things: Services and Applications Categorization. Adv Internet Things. 2011;1(2):27-31.

6. Almada Lobo F. The Industry 4.0 revolution and the future of Manufacturing Execution Systems (MES). J Innov Manag. 2016;3(4):17.

7. Leitão P, Colombo AW, Karnouskos S. Industrial automation based on cyber-physical systems technologies: Prototype implementations and challenges. Comput Ind. 2016;81:11-25.

8. DS, Hung-An Kao JL, Wenjing Jin. Industrial Cloud-Based CyberPhysical Systems. 2014. 